\title{
The Impact of Father's Health on Reproductive and Infant Health and Development
}

\author{
Milton Kotelchuck
}

\section{The Importance of Enhancing Father's Health and Engagement During the Perinatal Reproductive Health Period to Improve Maternal and Infant Health and Development and His Own Life Course Health}

This, the first of two related chapters, provides a broad overview, and new conceptualization, of the various ways in which father's health impacts reproductive and infant health and development. It is paired with a subsequent chapter that examines the ways in which fatherhood influences the health and development of men (Kotelchuck 2021). These chapters endeavor to bring to light the heretofore underappreciated topic of father's importance and necessary active involvement in reproductive health and health care to enhance infant, maternal, family, and men's own health and development outcomes. Fathers' increased participation in reproductive health care activities, their actions on the ground, are perhaps outstripping the public health research and conceptual theories about their role and importance.

Traditionally, the principal focus of the Maternal and Child Health (MCH) field (and closely aligned Obstetric, Pediatrics and Nursing fields) has been on the mother's health and behavior and its impact on reproductive and infant/child health and development outcomes. Reproductive health and early parenting has been perceived as primarily, if not exclusively, the mothers' responsibility and her cultural domain, and to a significant extent fathers and men have been excluded.

This chapter does not argue to diminish the importance of women's health and reproductive responsibility, but rather seeks to expand upon and complement her

\footnotetext{
M. Kotelchuck $(\bowtie)$

Harvard Medical School and Massachusetts General Hospital Fatherhood Project, Boston, MA, USA

e-mail: mkotelchuck@mgh.harvard.edu
} 
role with an enhanced paternal and family perspective on reproductive and infant health and development and to encourage greater equity in parental responsibility and engagement in reproductive and infant care. Increased paternal involvement in the perinatal period is not a zero-sum game. This chapter focuses on fathers, by far the largest group of women's partners, but it does not presume that traditional two parent families are the only form of families that can raise healthy children; perhaps some of the lessons learned here will apply to all additional parental partners.

First, there is a large, well-established, and growing literature demonstrating the positive impacts of fathers' involvement on multiple facets of child development and family relationships (e.g., Yogman et al. 2016; Lamb 1975, 2010), which co-authors in this volume further discuss (Yogman and Eppel 2021). Fathers' participation, roles, and potential contributions during the perinatal time period (e.g., preconception, pregnancy, delivery, and very early infant life and family formation) are by comparison a very under-studied topic. This chapter will explore how fathers' multifaceted perinatal involvement and health improves reproductive and infant health outcomes; and more explicitly expand our understanding of men's life course development and responsibility, as fathers, into an earlier temporal period before delivery.

Second, the limited research on the father's contribution to perinatal health can be found across very scattered sets of MCH literature-with often seemingly random observations and assessments of possible paternal causal mechanisms and associations. Hopefully, this chapter will help to coalesce these many diverse threads of research into a more systematic organized framework-in order to better facilitate further discussion, analysis, and ultimately action around enhancing fathers' contributions to reproductive/perinatal health.

Third, many of the conceptual themes about fathers' health in this chapter build upon similar themes from an earlier preconception health and fatherhood article (Kotelchuck and Lu 2017), but here move beyond its more limited preconception health time frame, explore additional new evolving paternal reproductive health themes, and separate the impacts on infants from impacts on fathers. This chapter adopts a very broad holistic approach to men's health, blending mental, physical, genetic, social health dimensions and some health service utilization themes into a single comprehensive fatherhood framework.

Fourth, this chapter, and the following one, model and build upon the current women's pre-conception health perspective in the $\mathrm{MCH}$ field, which simultaneously addresses the impact of the mother's pregnancy on both the infant's and the mother's own lifetime health (Moos 2003) - an intergenerational approach that respects the integrity and health of both mothers and infants simultaneously, without valuing one's life above the other (Wise 2008). These paired chapters adopt this same dual orientation.

Fifth, this chapter does not emerge in an ahistorical vacuum, but is linked to numerous ongoing political and professional movements. In particular, this chapter is partially embedded in (and contributes to) the larger evolving social and gender equity debates over roles and opportunities for women and men in society, especially the role of fathers, given that many aspects of parenthood are socially determined. 
This is also a period of substantial economic and cultural transitions, as fatherhood transforms from an older patriarchal model of fathers as distant, controlling economic providers with stay-at-home nurturing mothers to a newer model based on greater parental equity in childcare responsibilities and combined joint family incomes. This chapter also builds upon the U.S. National Academy of Science, Engineering and Medicine's (NASEM) multigenerational lifecourse-inspired movement to foster effective parenting and parenting health, recognizing that the "early caregiving environment is crucial for the long-term development of the child" and that "effective parenting presupposes the caregivers own well-being" (NASEM 2016, 2019a), but now expands upon these parenting themes to more actively include fathers.

Sixth, it is hoped that in articulating the multiple domains of fathers' impact on perinatal health, this chapter will guide more effective and targeted ameliorative interventions and policies that will encourage and enhance father involvement in perinatal health period (i.e., moving from theory to action), as well as provide a better framework to guide further research on this emerging topic. Moreover, beyond fathers' potential contributions to improve reproductive and infant health, the perinatal period may also add opportunities for improved men's health and better targeted primary care and mental health services.

This chapter specifically provides the scientific evidence base for the contribution of fathers' health and greater involvement in the perinatal period to healthier infants, families, and men themselves.

\section{The Impact of Father's Health on Reproductive and Infant Health}

There are multiple pathways by which the father's health and health behaviors can directly and indirectly impact on the reproductive and early life health and wellbeing of his children. This manuscript will note and briefly explore the current knowledge base within eight distinct domains of potential paternal impact.

1. Paternal planned and wanted pregnancies (family planning)

2. Paternal biologic and genetic contributions

3. Paternal epigenetic contributions

4. Paternal reproductive health practices that could enhance their partner's health behaviors and self-care practices

5. Paternal reproductive biologic and social health that could enhance their partner's reproductive health biology

6. Paternal support for maternal delivery and post-partum care

7. Paternal mental health influences

8. Paternal contributions to the family's social determinants of health 
Three of these eight pathways reflect pre-conception to conception influences (1-3); three reflect father-mother perinatal interactions (4-6); and two reflect systemic influences (7-8).

\subsection{Paternal Planned and Wanted Pregnancies (Family Planning)}

First, father's preconception health and health behaviors have a direct impact on maternal and infant health through family planning, one of the most traditional reproductive health and health service topic. Men are critical participants in family planning, with an inherently shared partnered responsibility (Grady et al. 1996); although traditionally, most family planning efforts have been directed at women, assuming it is their principle responsibility. Currently, in the U.S., men report between 35 and $40 \%$ of the births are unintended, 27\% mis-timed, and 9\% unwanted. Rates vary substantially, with more unintended pregnancies among young, unmarried, low-income, and minority women, especially those with non-residential partners (Lindberg and Kost 2014; Mosher et al. 2012).

Planned and wanted pregnancies are associated with healthier birth outcomes, especially decreased low birthweight (LBW) and pre-term births (PTB) (Kost and Lindberg 2015; Shah et al. 2011; Tsui et al. 2010). More generally, family planning is associated with improved birth spacing, smaller family size, fewer abortions, especially unsafe abortions, and fewer sexually transmitted infections (STI) (Tsui et al. 2010). Active paternal family planning efforts thereby also further mitigate against adverse maternal health behaviors associated with unwanted pregnancies (including less folic acid consumption, increased smoking, elevated maternal stress, less prenatal care and less subsequent breastfeeding) (Cheng et al. 2009; Kost and Lindberg 2015). Unplanned pregnancies are associated with a wide array of negative health, economic, social, and psychological outcomes for the mother, child, and family — both in the U.S. and throughout the world (Brown and Eisenberg 1995).

Planned and wanted pregnancies are associated with greater paternal engagement during pregnancy, childbirth, and postpartum periods (Bronte-Tinkew et al. 2007; Redshaw and Henderson 2013). By contrast, unplanned pregnancies are associated with lessened willingness of fathers to form and sustain family relationships, to live with the mother and child, to remain involved and support them, or to more positively self-appraise their own fathering quality and identity (Linberg et al. 2016).

Family planning is a reproductive health service that directly offers men the opportunity to improve their own health status: to obtain and use effective contraceptive methods, to prevent and treat STIs, and to address their subfertility issues. Increasingly national and state public health efforts are targeting men to encourage their family planning responsibilities and assure access to needed family planning services. Yet only $12 \%$ of men of reproductive age in the United States reported receiving family planning services, birth control, or STD screening services in the 
prior year (Chabot et al. 2011). "Still, the sexual and reproductive health needs of men in their own right - as individuals and not simply as women's partners-have been largely ignored" (Wulf 2002). The first recommendation in the seminal U.S. report on Preconception Health and Health Care calls for partners separately and together to prepare a reproductive life course plan (Johnson et al. 2006). The Centers for Disease Control and Prevention (CDC) has implemented separate men's and women's preconception and family planning websites to improve the chances of healthy planned, conceptions (CDC 2019a). And the U.S. Office of Population Affairs, Title X Family Planning administrators, have now for the first time explicitly mandated clinical guidelines for quality men's family planning and related preconception health services (Gavin et al. 2014).

Europe, in general, has more effective and equitable family planning educational and contraceptive policies than U.S., which perhaps contributes to their less frequent unintended pregnancies (Sedgh et al. 2014) and healthier reproductive outcomes (MacDormand and Mathews 2010). Men's sexual and reproductive health programs are also important to international development agencies, which focus extensively on men's involvement - and, too often, non-involvement or lack of responsibilityin family planning. These programs cover a broad range of topics including: avoidance of unwanted pregnancy; HIV/STI prevention; promotion of women's reproductive health; gender norms and couple communication; intimate partner violence prevention; and promotion of fatherhood (see, e.g., Sternberg and Hubley 2004), although the effectiveness of such interventions for men has been questioned (Hardie et al. 2017).

Paternal family planning (and preconception health care) services ensure that all pregnancy risks and responsibilities are not held solely by women. They provide a locus to enhance future reproductive outcomes through the practical encouragement of planned and wanted pregnancies and the enhancement of men's own health. Family planning promotion and services, a major area of current public health interventions, address a key pathway by which fathers can enhance reproductive and infant outcomes. Given how many pregnancies are unplanned, there remains much room for family planning enhancements, utilization, and targeting. Disappointingly, the relatively extensive maleoriented family planning services are not built upon during the subsequent fatherhood journey into the antenatal period and beyond.

\subsection{Paternal Biologic and Genetic Contributions}

Second, father's reproductive health, through his genetic contributions, has a direct biologic impact on his infant's health and development. Father's genes reflect half of the child's genetic inheritance. This pathway-father's genetic contributions, his sperm - is the most traditionally conceptualized domain for father's direct biologic responsibility and contribution to his child's subsequent health and well-being (and his/her appearance, personality, and intelligence among other themes). And this is 
often viewed as his only direct biological means of reproductive influence. Moreover, historically in patri-centric cultures, a father's genetic contributions have provided the legal basis to assert his progenitor control over his offspring and to assure the inheritance of societal property, his social determinants of health (SDOH) status and characteristics.

Three inter-related issues are important to successful procreation of healthy non-genetically compromised children: sperm quantity (getting pregnant), sperm quality (assuring a healthy fetus), and men's preconception health, the precursor to both. Each of these reflects long-standing traditional areas of public health research and practice.

Threats to sperm quantity. First, there are increasing reports of threats to the quantity of men's sperm, and therefore to his biologic capacity to impregnate women (e.g., Carlsen et al. 1992). A meta-analysis by Levine et al. (2017) suggests a 52.4\% decline in men's sperm concentration and 59.3\% decline in sperm count in Western countries in the last 40 years. And these declines are coinciding with increasing incidence of related cryptorchidism, hypospadias, and male testicular cancer (Carlsen et al. 1992; Levine et al. 2017).

Numerous reports document the extensive range of threats to the quantity (and quality) of men's sperm (e.g., Frey et al. 2008; Levine et al. 2017). Major threats include occupational and environmental influences (e.g., radiation, lead, endocrine disrupting chemicals); lifestyle factors (e.g., smoking, alcohol, high BMI); genetic disorders and chronic diseases (e.g., cystic fibrosis or diabetes); medicines (e.g., anabolic steroids, cancer chemotherapies); and demographic factors (e.g., paternal age).

Male infertility and subfertility represent a substantial direct biologic reproductive health problem. Impaired fecundity effects 13\% of U.S. women (CDC 2019b). The decline in male sperm quantity likely contributes to the high rates of the total infertility due to male infertility factors alone $(\sim 30-40 \%)$ or joint male/female infertility factors ( 10-20\%) (Kumar and Singh 2015; Argwal et al. 2015). Infertility also can be a reproductive mental health stress for men, women, and families; male infertility is associated with increased family stress, low self-esteem, embarrassment, and depression (Noncent et al. 2017).

Threats to sperm quality. Second, similar to the quantity of men's sperm, the quality of men's genetic contributions can also strongly influence reproductive and infant health and development. Sperm quality can be damaged through a variety of mechanisms (e.g., immature sperm cells, DNA fragmentation, single or double strand DNA breaks, abnormalities of semen, testicular damage, sperm motility, etc.) (de Kretser 1997). Almost all of the prior risks for reduced sperm quantity have also been associated with sperm quality (Frey et al. 2008; Levine et al. 2017), and new risks continue to be established. On a more positive note, some damaged sperm can be replaced, as sperm regenerates every 42-76 days (de Jonge and Barratt 2006), and many of the clinical, environmental, and health behavior risk factors can be prevented or minimized.

There is a trend towards increasing number of births to older fathers in developed countries. Notably, advanced paternal age has been associated with poorer birth 
outcomes (stillbirths, preterm births); increased congenital anomalies (especially Down syndrome and PDA heart defects); and childhood acute lymphoblastic leukemia, autism, and schizophrenia (Andersen and Urhoj 2017), all of which are linked to increased de novo paternal genetic mutations that increase with age (Kong et al. 2012). Additionally, there is a well-established MCH epidemiologic literature demonstrating stable cross-generational father and infant/child characteristics, including height and weight, birth weight, and prematurity history (e.g., Misra et al. 2010; Shah and the Knowledge Synthesis Group on Determinants of Preterm/Low Birthweight Births 2010), although the causal mechanism for these associations may not operate only through direct genetic pathways.

Men's preconception health. Third, efforts to enhance men's successful fertility, via the quantity and quality his sperm, have infused the growing men's preconception health efforts (Kotelchuck and Lu 2017; Garfield 2018). Men's targeted preconception health sites exist, but they mostly encourage personal responsibility and behaviorally focused preventative approaches. Societal and employment policies, such as environmental toxic exposures regulations or community-wide lifestyle improvements or public awareness campaigns, could also be very influential. Primary care clinical approaches targeted at men's preconception health are just now being developed (Frey et al. 2008; O'Brien et al. 2018), however too few men receive any formal preconception care services, despite evident need (Frey et al. 2012; Choiriyyah et al. 2015). Men's preconception interventions could not only enhance his sperm quantity and quality but could also promote his health more generally over his lifetime.

Men's (sub-) fertility and the potential for impaired genetic quantity and quality of his sperm is the most traditionally conceptualized pathway for men's direct biologic impact on reproductive and infant health and developmentplus it is a pathway that influences men's own health and development. While an extensive basic, epidemiologic, and clinical research literature exists addressing men's fertility, including a nascent focus on men's preconception health interventions, this pathway still remains understudied and underappreciated. Given how few births are planned, too many fathers are not optimally prepared for their healthiest conceptions.

\subsection{Paternal Epigenetic Contributions}

Scientifically father's sperm (his genetic germ line) has been, heretofore, viewed as the only direct biologic means to influence the infant's health, yet emerging today is another newly discovered and important direct biologic mechanism, epigenetics, by which men's sperm continues to differentially influence fetal maturation and child development long after the procreation of that infant. Epigenetics can be viewed as an on/off switch for genes based on a man's lived experiences (technically through gene methylation, histone modification, and mitochondrial RNA expression). It represents an exciting new pathway by which father's own current well-being and 
health experiences, a kind of Lamarckian genetics, influences his gene's expression and amends its original genetic contributions to the health and development of his child - and possibly alters his genetic expression over subsequent generations. More broadly, this pathway derives from our increasing scientific understanding of how environmental influences can alter (epigenetically) parental gene expression and ultimately changes the phenotype and behavior/health trajectories of their offspring. It also reflects new thinking about how our species can more rapidly adapt to changing environments, beyond the long periods needed for the genetic adaptation of the fittest.

While the epigenetic field initially focused on the mothers contributions, given that fathers contribute half of the infant's genetic material, paternal epigenetic contributions to perinatal and child well-being has recently emerged as a rapidly developing, though still small, basic science and clinical research area (Hehar and Mychasiuk 2015; Day et al. 2016; Soubry 2018). Soubry (2018) coined the term "POHaD," Paternal Origins of Health and Disease, to describe this newly emerging conceptual area. To date, most paternal epigenetic research utilizes animal models, though there is some limited literature demonstrating epigenetic transformations and impacts in humans.

Diet. Epigenetic changes in their offspring have been associated with father's diet. A growing epidemiologic literature shows that fathers' weight and BMI status independently influences the birth weight, obesity, and diabetes of their offspring (e.g., Dodd et al. 2017). For example, during Swedish famines, low and high food availability in pre-pubescent adolescents males led to changes in their children's and grandchildren's obesity, diabetes, and cardiovascular health, especially among sons, independent of their mother's health and food exposure; these were epigenetic changes too fast for spontaneous genetic alterations (Brygren et al. 2001; Kaati et al. 2002). A wide range of paternal dietary changes in experimental studies in animal models have led to marked epigenetic metabolism and tissue modifications in their offspring (Soubry 2015). Soubry et al. (2016) have shown epigenetic marker differences between obese and lean men in the cord blood DNA methylation among their offspring. Men's pre-conception physical health characteristics, such as men's diabetes, have been associated with sub-optimal birth outcomes (Moss and Harris 2015).

Alcohol and smoking. Paternal drinking/alcohol consumption is associated with epigenetic changes in their offspring. Heavy paternal alcohol intake has long been known to impact reproductive and child's health and developmental outcomes (Finegersh et al. 2015). Seventy-five percent of children with Fetal Alcohol Syndrome Disorders (FASD) have alcoholic fathers-even in the absence of maternal alcohol consumption (Day et al. 2016). Paternal alcohol exposure in rodent studies alters their sperm's DNA and offspring's epigenetic characteristics, and is associated with a variety of alcohol susceptible features in their offspring, including low birth weight and hyper-responsiveness to stress, also commonly seen in children with FASD (Day et al. 2016). Similarly, paternal pre-pubertal tobacco smoking has been linked epidemiologically to their children's obesity and asthma (Northstone et al. 2014; Svanes et al. 2017); and in animal studies, pre-conception smoke exposures 
have been associated with epigenetic changes in transcription factors and miRNA (Day et al. 2016).

Other environmental and behavioral factors. Soubry (2018) documents a series of other environmental exposures in fathers that are associated with epigenetic changes in their sperm or offspring, including organophosphate flame-retardants, Vitamin D supplementation, and exercise. In rodent studies, paternal stress prior to conception has been shown to alter methylation patterns and gene expression associated with their offspring's brain (Rodgers et al. 2013), HPA axis blunting (Dietz et al. 2011), and increased depressive and anxiety-like behaviors (Mychasiuk et al. 2013). Men's pre-conception elevated lead blood levels are associated with sub-optimal birth outcomes (Esquinas et al. 2014).

A note of caution however, most epigenetic research studies are based in rodent models; human studies are relatively rare and often not sufficiently rigorous. Furthermore, some of the purported paternal effects may be due to maternal or fetal compensatory behavioral changes adjusting to the father's altered characteristics (Curley et al. 2011). The intergenerational permanence of the environmentally induced epigenetic effects in the paternal germ line also remains under-explored, especially in humans. Epigenetic changes, however, do suggest plausible biologic mechanisms by which some of the previously noted paternal sperm quality risk factors and epidemiologic environmental exposures (including older age) are associated with poorer reproductive and infant health outcomes.

The emergence of paternal epigenetic pathways provides exciting new biological insights into how father's preconception and ongoing current health status, health behaviors, and environmental exposures can directly impact fetal, infant, and child's health and development over their lifetime and intergenerationally. Epigenetics, a kind of Lamarckian genetics that compliments Mendalian genetics, provides a richer understanding of how father's social and health experiences, his lived experiences, enters into his body and then influences the quality of his sperm and its genetic and, now, epigenetic contributions to his offspring's health and development. These "lived" gene experiences are still a new area of research, and their practical clinical implications are not yet developed. No longer should only women or only pregnant women be encouraged to be healthy to assure their future infant's health, but now fathers should be too; their own current health status and behaviors may have a direct epigenetic influence on their infant's health.

\subsection{Paternal Reproductive Health Practices That Could Enhance Their Partner's Health Behaviors and Self-Care Practices}

Paternal reproductive practices have an indirect impact on the infant's health through their encouragement of enhanced or diminished reproductive health 
behaviors and self-care practices of their partners. Father's own health care, behaviors, and attitudes offer opportunities to support, model and promote positive women's reproductive health and health care seeking behaviors.

Enhancing maternal health behaviors. Fathers can serve as a role model to foster or discourage maternal preventative health-related behaviors-which can directly influence reproductive outcomes-both before conception and during pregnancy. For a woman to eat nutritiously, quit smoking, exercise, and not use drugs, etc., can be more difficult if her enabling partner continues his reproductively negative health behaviors. There is an extensive literature on the co-occurrence of maternal and paternal negative health behaviors across a wide range of reproductive health promoting behaviors, including alcohol usage (e.g., Leonard and Eiden 1999), smoking (e.g., Gage et al. 2007) and dietary habits (e.g., Saxbe et al. 2018). A woman, for example, is 6.2 times as likely to be obese if her partner is obese compared to normal weight (Edvardsson et al. 2013). Fathers who are more actively engaged and socially supportive during the pregnancy are associated with reduced maternal cigarette consumption (Martin et al. 2007; Elsenbruch et al. 2007; Cheng et al. 2016; Bloch et al. 2010) and drug usage (Bloch et al. 2010). Fathers are an important antenatal and postnatal influence on mother's breastfeeding decisions and success (Bar-Yam and Darby 1997; Wolfberg et al. 2004; Rempel and Rempel 2011), and greater paternal involvement is associated with more breastfeeding (Redshaw and Henderson 2013). Improving father's antenatal reproductive health behaviors also directly benefits the father's lifetime health.

Enhancing maternal reproductive health service utilization. Fathers can play an important role in encouraging or discouraging women's utilization of prenatal care (PNC) and other reproductive and pediatric health services. Fathers who were more actively engaged during their partner's pregnancy were more likely to encourage earlier and more frequent prenatal care (Martin et al. 2007; Teitler 2001; Redshaw and Henderson 2013) and more postnatal care (Redshaw and Henderson 2013). PNC utilization was less adequate among couples with disagreement about the pregnancy wantedness (Hohmann-Marriott 2009) and earlier among fathers desiring the pregnancy in a Hispanic sample (Sangi-Haghpeykar et al. 2005). Recognizing that fathers can also be a controlling gatekeeper in decisions around maternal usage of reproductive health services - a role that varies within different cultural groups - fathers could be more actively targeted to encourage their partner's PNC usage, similar to the messages now routinely directed at them to support their partner's breastfeeding.

Providing maternal emotional and logistical support to influence maternal health behaviors. Fathers can be a major source of emotional, logistical, and financial support or stress for their partners during pregnancy and early parenthood (May and Fletcher 2013; Alio et al. 2013); and in general, increased maternal stress is strongly associated with poorer pregnancy outcomes (Wadhwa et al. 2011; Lu and Halfon 2003). More paternal emotional support and involvement during pregnancy is widely associated with less maternal anxiety, stress, and depression (Elsenbruch et al. 2007; Cheng et al. 2016; Bloch et al. 2010), and with less post-partum maternal psychological stress (Redshaw and Henderson 2013). Elevated maternal stress can 
lead to the adoption of reproductively unhealthy coping behaviors (Lobel et al. 2008; Hobel et al. 2008; Bloch et al. 2010), a possible causal pathway for poorer pregnancy outcomes. Conceptually, this topic encourages fathers to provide the traditionally ascribed positive "support" for their partners during pregnancy.

Women with more direct paternal emotional support during pregnancy (as well as practical or financial support) are associated with better birth outcomes, in low-income Black urban communities (Bloch et al. 2010), in Latin communities with moderate-high stress levels (Ghosh et al. 2010), and among smokers (Elsenbruch et al. 2007), although such findings are not always strong or consistent across all populations (Cheng et al. 2016). Paternal emotional support, as an isolated variable, may not be sufficient to counteract the stronger, longitudinal maternal reproductive health stresses prevalent in low-income communities. Birth certificate analyses of women in father-absent or single-parent households, who would theoretically have less paternal emotional support (as well as less financial support), have poorer birth outcomes (Gaudino et al. 1999; Alio et al. 2011a; b; Hibbs et al. 2018).

Most fathers want to, and can be encouraged to, help ensure healthier offspring by promoting their partner's positive reproductive health behaviors and self-care practices and by diminishing her need to adopt negative stressrelated coping behaviors. This indirect paternal reproductive health pathway encourages the traditional supportive roles for fathers during pregnancy. The importance of these efforts however is often under-appreciated; too many fathers unfortunately do not sufficiently model or promote positive health behaviors, nor provide enough emotional, logistical, or financial support. This pathway also encourages fathers to simultaneously improve their own health and health behaviors during the perinatal period, and possibly to enhance the epigenetic health of their future children.

\subsection{Paternal Reproductive Biologic and Social Health That Could Enhance Their Partner's Reproductive Health Biology}

Father's health status and health behaviors can have a direct positive, neutral, or negative impact on the physical and biological health of the pregnant woman and her developing fetus. Or, stated alternatively, the absence of father's negative health status and negative health behaviors can enhance (and/or not harm) the woman's and fetus's reproductive health status during the pregnancy. Conceptually, there are multiple channels through which the father's influence can be manifested. The negative modalities are the more popularly known.

Intimate partner violence (IPV). Sexual violence and reproductive control, disproportionately targeting women of childbearing age, especially younger and poorer women, is a direct threat to the reproductive health of the mother and fetus. Though the vast majority of fathers do not engage in IPV, 3-9\% of women report 
being abused during pregnancy (Chu et al. 2010; Chen et al. 2017), with slightly lower rates reported in Europe and Asia and higher rates in the Americas and Africa (Devries et al. 2010). IPV is associated with a wide range of maternal reproductive health problems (including unintended and rapid repeat pregnancies, increased STIs); maladaptive coping behaviors; serious mental health problems (including pre- and post-partum depression); and poor infant outcomes (including prematurity and infant mortality) (Alhusen et al. 2015). IPV and injuries are the leading cause of maternal mortality, with IPV associated with $~ 50 \%$ of pregnancy related suicides and homicides (Palladino et al. 2011). But importantly, by implication, this means that lack of IPV by fathers is associated with neutral or better birth outcomes for mothers, infants, and families. A wide variety of men's IPV prevention interventions have been implemented, most heavily focused on addressing the masculinity and gender-related social norms implicated in violence. These have proven only marginally effective, and more community-based ecological approaches are now being advocated (Jewkes et al. 2015). The concerns of women's health care providers about the possibility of IPV, and their ability to inquire about IPV confidentially, have often led to the discouragement of, and even hostility towards, fathers participating in maternal reproductive health services during pregnancy (Davison et al. 2019).

Sexually transmitted infections. Fathers with sexually transmitted infections (STIs), can potentially expose their pregnant partners and through them their fetuses to these infectious diseases. The prevalence of STIs in men is substantial and varies by infection; one in two sexually active men will contract a STI by age 25 (ASHA 2019). Untreated STIs are associated with a wide range of poor birth outcomes (including miscarriages, PTBs, infant mortality, and infant eye, lung, or liver damage); maternal morbidities (including pelvic inflammatory disease and tubule infections, that increase the likelihood of infertility); as well as paternal morbidities (including systemic infections, infertility, penile cancer, sores/flare ups and death) (CDC 2019c). Since most STIs can be prevented or well managed through safe sex and antibiotics, fathers must play a key role in their prevention, treatment, and mitigation - a responsibility towards both the current and future pregnancies. Yet, only $12 \%$ of adolescents and young adult men are formally screened for STIs annually (Cuffe et al. 2016). STI treatment of women without simultaneous treatment of their infected male partners is doomed to failure.

Paternal infectious diseases. Beyond STIs, the father's exposures to other infectious diseases can serve as a direct vector for their introduction to their partners (e.g., rubella, chicken pox, tuberculosis, Zika, and coronavirus). Recently, CDC/AAP has begun advising fathers to obtain the Tdap vaccines during the pregnancy to ensure a healthy environment during the infant's early life vulnerability to pertussis; and similarly to obtain annual influenza vaccinations (CDC 2011).

Paternal second-hand smoke and other environmental exposures. In metareview articles, household second-hand smoke (SHS) exposure among non-smoking pregnant women is associated with a small but significant decrease in infant birth weight (Salmasi et al. 2010; Leonardi-Bee et al. 2011). SHS exposure during pregnancy has been also associated with an increased risk of infertility, stillbirth, 
and pre-term delivery (Meeker and Benedict 2013). The only SHS intervention specifically directed at fathers showed positive impact on paternal quitting rates (Stanton et al. 2004). Beyond SHS, fathers may potentially expose women to a variety of other teratogenic and mutagenic occupational and environmental toxins (Knishkowy and Baker 1986). Infants born to the partners of U.S. and Australian soldiers in Vietnam who handled Agent Orange/dioxin had increased birth defects (Ngo et al. 2006). Paternal pre-conception and perinatal health care screenings potentially allows for the mitigation of maternal and fetal exposure to environmental toxins (Frey et al. 2008).

Direct paternal influence on maternal and child nutritional status. Beyond the already noted indirect pathways by which fathers can encourage positive or negative maternal nutritional health practices, fathers can play an important direct role in influencing maternal weight gain, obesity, and nutritional status during pregnancy and beyond. Fathers are not necessarily passive bystanders in the nutritional well-being of their households. They can potentially directly influence food and meal preparation, household food and beverage purchases, formal dining practices, and the availability of needed family income to obtain adequate nutrition. More men cook and spend more time cooking now than over the past 40 years (Smith et al. 2013). There is increasing theoretical recognition that fathers could directly contribute to infant obesity prevention and metabolic health, perhaps starting even prior to birth (Davison et al. 2019), yet few nutrition interventions directly target fathers (Morgan et al. 2017; Davison et al. 2017). Father's own weight is an independent predictor of childhood obesity (Freeman et al. 2012; Dodd et al. 2017).

Stress and its direct impact on maternal reproductive health biology. Paternally induced stress can be harmful to mothers and their developing fetuses through multiple direct and indirect modalities, and may even have lifelong impacts. Previously in this chapter, maternal response to elevated stress through maladaptive health behaviors was viewed as an indirect causal pathway. Here, additionally, elevated maternal stress is viewed as having a direct causal effect on women's reproductive biology, impacting her developing maternal-placental-fetal endocrine, immune, vascular, and genetic systems, as well as through the effects of stress on nutrition utilization and stress on infectious disease susceptibility (Wadhwa et al. 2011; DiPietro 2012). Both humans and animal maternal stress models (often paternally induced) have repeatedly documented changes in cortisol and corticotropinreleasing hormone (CRH) levels, hypothalamic-pituitary-adrenal (HPA) axis functioning, vascular changes, hypertension, etc. (Wadhwa et al. 2011; NASEM 2019a), reflecting biologic changes widely hypothesized as the physiologic basis for pre-term births, Black-White infant reproductive disparities, and sub-optimal African-American women's health over their life-course (e.g., the "weathering hypothesis" Geronimus 1992, 1996). Moreover, the direct biologic impact of increased maternal stress may have long-term epigenetic consequences on the infant's brain and behavioral response to stress. Furthermore, if the biological responses to stress interact with increased negative maternal pregnancy behaviors, they may 
perhaps further foster epigenetic dietary and metabolic disease, alcohol susceptibility, etc. in their offspring (Wadhwa et al. 2011).

Father's health and social health behaviors (both positive and negative) during the perinatal period can have a direct biologic impact on maternal and fetal/infant health and development. Beyond the widely noted concerns over IPV and STIs, father's health operates through multiple other modalities to impact the mother's reproductive health biology. Father's health (after procreation) is not usually thought of as a direct mechanism or pathway to influence reproductive outcomes, but it should be. This is an important new and expanding conceptual pathway for paternal reproductive health impact. Moreover, addressing father's reproduction-linked health issues will directly enhance his own lifetime health, as well as enhance the reproductive health biology of women and their fetuses in the current and future pregnancies.

\subsection{Paternal Support for Maternal Delivery and Post-partum Care}

Fathers can impact reproductive and infant health through their active and direct provision of clinical support to their partners during the perinatal period, especially around delivery and post-partum care. This is a new emerging conceptual pathwayfathers as direct quasi-health care providers for their partners. For example, in most marriages or stable relationships, partners provide palliative and supportive functional nursing care when their partner is sick. During the perinatal period, fathers can and often do provide some very specific maternal reproductive health services.

Obstetric emergency support: Fathers can potentially prevent maternal and infant mortality and morbidity by recognizing and acting on obstetric emergencies, especially for very premature deliveries, as delays in getting antenatal clinical interventions can have serious maternal or fetal consequences. Thaddeus and Maine (1994) emphasized that fathers should be able to recognize an obstetric emergency, be able to take decisions to seek care (or encourage their partner to seek care), and be able to transport their partners to high quality health services. The European WHO agency sees these as some of father's principle antenatal responsibilities (WHO 2007). Most fathers provide ambulance-like transportation to the delivery hospitals for their partner's premature and normal gestation pregnancies.

Delivery support: Fathers can play an important supportive role for mothers during delivery. Starting in the later part of the twentieth century, fathers have been increasingly present in hospital delivery rooms, providing familial emotional reassurance and practical support to their partner during her birthing experience. Recent figures suggest that up to $90 \%$ of fathers in Britain are present at delivery (Redshaw and Heikkilä 2010), with nearly universal participation in most western countries today (Redshaw and Henderson 2013). Historically, the women's reproductive health movement led the fight for their partner's presence in the birthing room 
(Leavitt 2010). Many women view their partner's presence as a secondary advocate or advisor on emergent obstetric decisions, independent of the clinician-centric hospital culture. Conceptually, these paternal delivery support roles are analogous to some of the roles of a doula (e.g., Dads as Doulas.) Many fathers themselves also now want to be present at delivery for their own emotional and psychological growth and infant bonding.

There is very limited systematic research on the impact of father's presence in the delivery room to date. These are mostly small case series, some reporting more positive impact for the mothers and the fathers (Kainz et al. 2010), and others reflecting more mixed experiences (Bohren et al. 2019), especially for first time fathers who may be unfamiliar or uncomfortable with obstetrical practices during delivery (Johansson et al. 2015; Jomeen 2017). Moreover, many clinicians are resistant to their presence in the delivery room and do not always treat them favorably, i.e., "not patient, not visitor," and hindering fathers' desires to be more supportive (Steen et al. 2012). However, accommodating the increasing father delivery participation trends, many birthing centers now provide supportive fatherfriendly post-partum sleeping accommodations for both parents.

Post-partum recovery care and support. Following the birth, many fathers provide instrumental help, social support, and nursing-like health care for the mother during her post-partum recovery, especially for post-operative Cesarean sections care, as well as begin to provide newborn and family care. In situations where the mother's or infant's health is seriously compromised, fathers often must take on more emergency or even full-time care of their newborns and be a resource to help manage the mother's emotional and practical needs (Erlandson and Lindgren 2011). And, if an infant is premature, many Neonatal Intensive Care Units (NICUs) now encourage paternal skin-to-skin kangaroo care to reduce neonatal morbidity and facilitate neuro-behavioral development (Ludington-Hoe et al. 1992).

Paternal leave. Beyond the father's own potential desire for infant bonding, paternal post-partum leave allows the time and space to provide more supportive nursing care for his partner. Paternal leave's impact may operate through the mother's well-being; increased paternal workplace paid-leave flexibility is associated with reduced maternal post-partum physical health complications and improved mental health (Persson and Rossin-Slater 2019). While a large literature documents the health and developmental benefits of paid leave for mothers (Gault et al. 2014), less research exists on the paternal leave benefits. Longer paternal leave is associated with greater subsequent infant and childcare involvement (Boll et al. 2014; Huerta et al. 2013; Nepomnyaschy and Waldfogel 2007).

Maternal post-partum depression observer. Finally and importantly, fathers are the frontline mental health observers of maternal post-partum depression (Garfield and Isacco 2009). They would be the first to notice emerging mental health problems and could act on that knowledge, perhaps even before a clinician's awareness. This responsibility is similar to the initial antenatal paternal responsibility for monitoring obstetric emergencies, only now in the post-partum period.

This emerging domain reflects a new reproductive health pathway for fathers as active and direct quasi-clinical care support for their partner. This 
role exists throughout the perinatal period, if not before and after, but is especially important around the delivery and the early post-partum period. This pathway potentially offers fathers the opportunity for more concrete action-oriented roles and contributions. Fathers, like doulas, can be a positive influence on maternal delivery and post-partum health experiences. The increased presence of fathers in the delivery room, and their provision of post-partum care, helps serve as a bridge between the father's antenatal reproductive health experiences and his subsequent post-natal family, parenting, and child health and development activities.

\subsection{Paternal Mental Health Influences}

Father's mental health status (including stress, depression, and anxiety) has a strong and well-established impact on multiple domains of child health and development (e.g., Yogman et al. 2016; Yogman and Eppel 2021, in this volume); however, there is very limited literature on the consequences of father's antenatal mental health on reproductive health or birth outcomes. By contrast though, there is a much larger literature on the impact of pregnancy on father's mental health (Kotelchuck 2021, in this volume). However, given the early origin implications of $\mathrm{MCH}$ life course theory, it is likely that father's antenatal mental health status may play an important role in reproductive and infant outcomes.

Paternal mental health functioning is a substantial health issue during the perinatal period. Perinatal period is associated with elevated rates of paternal depression (10.4\%) (Paulson and Bazemore 2010); anxiety (4-16\%) (Leach et al. 2016; Philpott et al. 2019); and stress (Philpott et al. 2017). Whether paternal antenatal mental health problems impact reproductive outcomes, or vice versa, may be a chicken-egg problem, but father's mental health status amplified by his pregnancy experiences needs to be addressed starting in the antenatal period.

The epidemiologic literature on paternal mental health status and birth outcomes is a very limited. In a Swedish population, Lui et al. (2016) documented that new onset paternal depression, though not chronic depression, was associated with elevated very preterm births. In animal models, paternal stress exposure in the preconception or antenatal periods has been repeatedly associated epigenetically with behavioral stress markers in their offspring (Dietz et al. 2011; Pang et al. 2017); and LBW has been documented among the offspring of paternally alcohol-exposed rodents (Day et al. 2016). Plus, as noted previously, the epigenetic consequences of paternal alcoholism, often a behavioral manifestation of mental health issues, is associated with FASD in their offspring (Finegersh et al. 2015).

The father's mental health status may be the underlying systemic source for several of the paternal perinatal reproductive health pathways discussed in this essay, especially those associated with increased maternal stress. Fathers who provide their partners with limited emotional and relational support may themselves have underlying mental health problems or limited relational skills. Men compared 
to women with depressive symptomatology often display higher levels of externalized irritability and anger, which may be particularly stressful for pregnant women (Madsen and Burgess 2010). Fathers with elevated mental health or stress symptoms may be a less reliable source of steady employment, financial security, or consistent practical help, important areas of maternal antenatal stress. Fathers often behaviorally self-medicate (e.g., increased alcohol and substance use) to avoid addressing their own mental health problems, which not only may add to the mother's stress, but further serves as a poor behavioral health role models for her. In the extreme, paternal mental health issues could manifest themselves in IPV or family abandonment. Ultimately, it is likely that all of the paternal reproductive health pathways discussed in this chapter reflect, in part, some paternal mental health components. However, to date, an appreciation of the secondary contribution of father's antenatal mental health to the other paternal reproductive health pathways is limited, a derivative topic at best.

Father's positive mental health status may help compensate for mental health problems of their partners. Engaged, non-depressed fathers have been shown to be developmentally protective for the infants and children with depressed mothers (e.g., Hossain et al. 1994; Mezilius et al. 2004), though this same theme hasn't yet been explored in the antenatal period. Father's positive mental health status may also play an important role in fostering a growing sense of paternal generativity and involvement starting in the antenatal period (Kotelchuck 2021, in this volume).

Finally and critically, paternal mental health issues can potentially be acknowledged, assessed, and treated even during the antenatal period. The men's preconception health literature exhorts them to improve their mental and behavioral health (CDC 2019a), but after conception little further attention is directed at this topic. Moreover, despite a nascent advocacy literature calling for attention to fathers often stressed and depressed mental health status during the perinatal period (e.g., Philpott et al. 2017; Gemayel et al. 2018), there are virtually no intervention programs directed at them during this period (Romanov et al. 2016).

Fathers experience substantial mental health challenges during the antenatal period. These may be underlying systemic contributors to many of the paternal reproductive health and health behaviors pathways, especially those associated with increased maternal stress, which ultimately may lead to poorer reproductive and infant health and development outcomes. This domain has not yet been sufficiently addressed by the larger reproductive health community, though it has been emphasized importantly within the child development and pediatric fields. Given the longitudinal assumptions underlying the MCH life course theory, paternal perinatal mental health is likely to be an important and emergent reproductive health topic in the future, similar to the recent increased focus on maternal antenatal depression. Unfortunately, too limited awareness of fathers' needs and too few mental health interventions are currently directed towards them in the perinatal period. 


\subsection{Paternal Contributions to the Family's Social Determinants of Health}

Finally, father's contributions to their family's social determinants of health, the family's social well-being, can be viewed conceptually as a "new" systemic pathway by which father's health and well-being impacts on reproductive, infant, family and their own health. Fathers are a key, and perhaps the dominant vector, for influencing the SDOH of their families. SDOH, in turn, are critically important factors for reproductive and infant health (Kotelchuck 2018; NASEM 2019a). The MCH public health field believes that differential family SDOH over the life course are the principle source of optimal or suboptimal lifetime health, and of social and racial health disparities manifested from birth outcomes onward (Lu and Halfon 2003; Pies and Kotelchuck 2014). Between 50 and $80 \%$ of health status is believed to be determined by SDOH, not medical care (Whitehead and Dalgren 1991).

The widely known positive stepwise gradient of better child health and development with higher family income or social class (e.g., NASEM 2016, 2019b) has been similarly demonstrated for reproductive outcomes (O'Campo and Urquia 2011). That more positive reproductive outcomes are associated with increasing father/ family income is a fact known and documented repeatedly since the 1920s (Woodbury 1925). More recently, for example, adverse birth outcomes throughout Canada were associated with decreasing father education, even controlling for maternal characteristics (Shapiro et al. 2017). Father-absent families, with their much lower incomes, have poorer reproductive and infant health outcomes than father-present families (Gaudino et al. 1999; Alio et al. 2011a, b; Hibbs et al. 2018). Residential geographic location, especially for poorer and minority families, is also strongly associated with poorer reproductive outcomes (O'Campo et al. 2008). European countries, which provide more extensive social welfare benefits to optimize their citizen's reproductive health and diminish social class disparities, have better infant and child health outcomes than the U.S., especially for prematurity and LBW (WHO 2017). And cross-generationally in Chicago, fathers from lower versus higher lifelong social classes, measured by neighborhood income from their own birth to their current paternity, had more infants with early and overall PTBs (Collins et al. 2019).

Father's social class, race, education, employment, and residence are not paternal "reproductive health choices"; they primarily reflect his birth and historical life circumstances, including exposure to systemic racism. Multiple mechanisms have been posited about how the negative structural aspects of paternal or family SDOH, especially those associated with poverty, get translated into poorer reproductive outcomes-limited access to healthier foods, poorer quality housing, more toxic environmental exposures, inadequate education, and poorer quality medical care, to name but a few (e.g., Braveman and Gottlieb 2014; NASEM 2019a, b). But beyond these more obvious direct structural aspects of $\mathrm{SDOH}$, there are also multiple other paternal-specific SDOH experiences that could influence reproductive outcomes.

First, the father's historic and current SDOH experiences influences his mental and physical health, which in turn further impacts reproductive and infant health 
outcomes. Fathers' own current health status diminishes as their income decreases or poverty level rises (Williams 2003), and their health is further compounded with their life course exposures to childhood poverty and adverse childhood experiences (ACEs) (Treadwell and Ro 2008). Poor and working-class fathers' health is impacted by their economic marginality, adverse working conditions, and greater work-life psychological stress and inflexibilities. Moreover, poorer men have less access to health insurance for themselves or their families (Cormon et al. 2009). Poor paternal health is thus both a consequence and cause of their poverty.

Second, as previously noted, father's SDOH or social well-being can directly and indirectly influence the mother's health, health behaviors and stress levels, which may impact reproductive and infant health outcomes. Poorer paternal SDOH may increase maternal stress over his reliability as a source of financial security and steady employment, his availability to provide consistent needed instrumental and emotional support, or his adoption of maladaptive coping behaviors to avoid addressing his own enhanced SDOH stresses.

Third, father's current social class or SDOH may limit his ability to participate in reproductive and infant health services. Poorer fathers' work schedules, in general, have less work flexibility (Gerstel and Clawson 2018), less time off to accompany their partners to antenatal, delivery, or pediatric care, and less paid newborn family leave-findings confirmed in our MGH fatherhood prenatal care study (Levy and Kotelchuck 2021, in this volume). These social class limitations can potentially diminish father's involvement with the pregnancy and infancy, reinforce traditional parental gender roles, and allow less attachment bonding time.

And finally, paternal SDOH can be conceptualized as a systemic influence that affects all the reproductive and infant pathways discussed in this chapter. For example, paternal poverty may limit access to contraceptive services and supplies; increase exposure to dangerous occupational or environmental toxins that impact sperm quality and quantity; or increase mental health stress and substance use that perhaps also are sources of paternal epigenetic transformations.

However, despite the discouraging epidemiologic associations between paternal poverty and poorer reproductive and infant outcomes, this paternal SDOH pathway does not simply represent a fixed permanent risk factor. It is amenable to broad integrated multifaceted policy and practice interventions to enhance paternal and family social well-being (Kotelchuck 2021). Kotelchuck and Lu (2017) outlined three broad domains of social interventions that are needed: paternal clinical policy and practice transformations; enhanced paternal social welfare and employment policies; and paternal agency and generativity programs.

Unfortunately, to over-generalize, in the MCH health care communities father's social status and well-being, beyond his presence or absence in the family and his insurance status, is not usually singled out as a special reproductive social determinant of health factor that needs to be formally addressed as a potential causal issue for poor maternal and infant health outcomes, but it should be.

Father's contributions to their family's SDOH can be viewed as a "new" foundational pathway by which father's health and well-being impact on reproductive, infant, family and their own health. Fathers are the key vectors 
for the social well-being/SDOH of their families, and SDOH are likely the most powerful direct influence on reproductive and infant health and development and their associated racial and social class disparities. Paternal SDOH operates systemically through multiple direct and indirect pathways, many of which are amenable to public programs and policies. However, given the general lack of interest in fathers in the $\mathrm{MCH}$ reproductive health communities, not surprisingly, this topic is rarely considered. One cannot ameliorate the SDOH root causes of poor reproductive health without directly addressing father's contributions to his family's SDOH.

\section{Significance of the New Father's Reproductive Health Conceptualization and Findings and Their Implications for Health Service Programs}

This chapter articulates eight broad pathways through which father's health, health behaviors and attitudes, and social well-being, directly and indirectly influences reproductive health and infant health. Men's contributions to reproductive outcomes are more than the quantity and quality of his sperm. This emerging conceptual framework covers the entire developmental span from preconception through pregnancy until birth and slightly beyond - a time period not usually thought of as reflecting paternal health influences on reproductive health outcomes (beyond his genetics at contraception), and perhaps beyond what most readers or $\mathrm{MCH}$ health professionals might currently think. Hopefully, this chapter will serve as a foundational scientific knowledge base for this evolving area of paternal reproductive health conceptualization and be used to support new and enhanced programs, policies, and research that encourage more active, healthier and earlier involvement of fathers during the perinatal period.

First, this chapter presents a broad systematic exploration of the father's multifaceted (biological, behavioral, and social) perinatal contributions to reproductive and infant health outcomes and a new eight-pathway conceptual framework to organize them. Heretofore, there has been only a very diverse and scattered $\mathrm{MCH}$ perinatal health fatherhood literature-focusing on a few specialized fatherhood themes (e.g., family planning or inter-generational birth outcome epidemiology) or targeted disease or intervention topics with a strong fatherhood emphasis (e.g., FASD/alcoholism or IPV initiatives). The proposed new conceptual framework builds upon an earlier and more limited one deriving from a men's preconception health paper (Kotelchuck and Lu 2017) — three of the proposed pathways reflect pre-conception to conception influences; three reflect father-mother perinatal interactions; and two reflect systemic influences. Among the pathways are several important new themes (including epigenetics, fathers as SDOH vectors); expansions of several traditional themes (especially father's direct ongoing health impact on mother's biologic health status); as well as several emerging themes (like father's 
quasi-clinical support of maternal delivery and post-partum care). Hopefully, others will build upon this initial conceptualization, as further new scientific understandings of paternal antenatal health impact emerge and evolve.

Second, this chapter has endeavored to push back the MCH field's appreciation of the developmental time frame for the father's impact on child development and early family life into the reproductive antenatal health period, if not earlier. This expanded time frame better aligns with the emerging scientific knowledge bases deriving from the MCH life course, Developmental Origins of Health and Disease (DoHAD), and First Thousand Days perspectives (Halfon et al. 2014; Wadwha et al. 2009; BlakeLamb et al. 2018). These perspectives emphasize that conception, or even earlier epigenetically, not the birth, is the true developmental starting point for the impact of both parent's health and well-being on their infant/child's life course risks and protective factors. This expanded temporal framework places fatherhood better into an intergenerational context - both as the source of his infant's health and well-being and as a bi-directional event for his own life's health and development. In addition, it reinforces the perspective that the earlier the father's involvement the better for the infant, family, and his own health. Historically, father's temporal contributions to child development have steadily moved to earlier and earlier ontogenetic time frames.

Third, this chapter's broad holistic view of father's health allows us to appreciate his impact on multiple reproductive and infant health domains simultaneously rather than focus only on single disease topics. This orientation is consistent with life course theory that early generic or upstream exposures impact multiple downstream disease-specific topics. Moreover, this chapter should expand our understanding that critical reproductive and infant health topics, such as nutritional health and dietary intake, substance use, stress, etc., can be, and are, impacted by several of the distinctive fatherhood conceptual pathways, perhaps at the same time. Indeed, for any critical reproductive health topic, one could examine each of the causative paternal health pathways and conceptualize their unique added contributions, thereby, increasing the number and timing of potential paternal interventions. Moreover, the eight specific pathways are written to try to isolate and better articulate them conceptually, but many of them overlap and are synergistic.

Fourth, as noted earlier, this chapter's themes are linked to numerous ongoing political and professional movements. First and most importantly, this chapter contributes to the evolving larger social and gender equity debates about the roles and opportunities for women and men in society. It contradicts the prevailing view that mothers alone are responsible for positive reproductive and infant outcomes. The infant's biology, beyond genetics, is a more shared responsibility than heretofore generally thought. Second, and not surprisingly, this chapter is being written during a period of major economic, social, and childcare transformations, with more than $70 \%$ of women with young children in the U.S. and other industrial countries now employed, and more single- and dual-income family fathers are now providing primary caretaking for their children during at least part of the day (Yogman et al. 2016). Third, this chapter expands upon the NASEM-inspired efforts to foster effective parenting and parenting health (NASEM 2016, 2019a); it explicitly 
highlights some potential additional and under-appreciated pathways to achieve those parenting goals during the antenatal period, beyond simply calling for parent's generic well-being and positive mental health status. Fourth, by recognizing the importance of father's SDOH contributions to reproductive outcomes, this chapter suggests that interventions focused only on maternal SDOH-related themes without also acknowledging or directly addressing the father's $\mathrm{SDOH}$ contributions are likely to fail. Moreover, social class differences in the parent's own health, including the fathers' health and mental health, are themselves a major source of developmental inequalities in reproductive and infant health. And finally, this chapter also emphasizes new reproductive health involvement dimensions to the emerging men's health movement.

Fifth, and importantly, this chapter also opens up a new empirical developmental science policy rationale for the father's increased, earlier, and healthier perinatal involvement. It documents the growing enhanced scientific knowledge base to support the emerging paternal perinatal health movements. Independent of one's ideological or policy rationale for supporting greater paternal antenatal involvement, the reality of his greater involvement (via his health and health behaviors) is objectively associated with better reproductive and infant outcomes.

Finally, the themes of this chapter (the impact of father's health on reproductive and infant health) and the next (the impact of fatherhood on men's health) are intractably bound. Fathers impact their child's health, and the child impacts the father's health, development, and generativity. Both perspectives are needed and critical; they coexist at the same time. The MCH field, which historically hasn't heavily emphasized the importance of fatherhood, must address this topic from the perspectives of both the child and family and the father himself - similar to the dual women's preconception health perspectives. One is not more important than another (Wise 2008).

\subsection{Implications for Health Services Programs and Policies}

This chapter's detailed recitation of the father's reproductive and infant health impacts hopefully should encourage more, and more well targeted, men's health care interventions across the lifespan for his family's and his own health. Antenatal reproductive health services for fathers are not currently a major focus of men's clinical health care. While a full discussion of antenatal reproductive health services or programs for fathers is beyond the scope of this chapter, I will simply note four broad health services transformations that would appear to be warranted: (1) Reorient current reproductive and pediatric health services to be more father or family inclusive; (2) Provide some father or family targeted health services during existing mother-focused reproductive and pediatric health services; (3) Encourage more reproductive health-focused primary health care for men; and (4) Increase mental health care for fathers in the perinatal period. Additional potential father-supportive prenatal care obstetric practices are discussed in the Levy and Kotelchuck (2021) 
chapter in this volume. New and emerging opportunities to foster more specific father-inclusive public health services or policies were also highlighted within each of the eight paternal pathways, where possible. Ultimately however, paternal health is only marginally impacted by the health or medical care sector; it is also deeply influenced by social welfare and employment policies (SDOH) directed at men, as well as father's own agency and generativity (see Kotelchuck and Lu 2017; Kotelchuck 2021). [Additional details about potential fatherhood enhancing programs and policies are discussed in other sectors of this book, and especially in the concluding chapter.]

\section{Conclusion}

Enhancing father's health and health behaviors before, during, after pregnancy, and in early parenthood is critical to improve reproductive and infant health and development, and ultimately the health of their families, communities, and the men themselves. This chapter articulates eight direct and indirect pathways by which father's antenatal health and health behavior, broadly construed, impacts reproductive and infant health. It brings together and expands upon the existing scattered fatherhood scientific knowledge base and pushes back the developmental time frame for father's reproductive health importance into the antenatal pre-birth period, if not earlier. Awareness of father's increased importance, involvement, and health during pregnancy and early family life should encourage a rebalancing of the culturally traditional maternal and paternal parental role expectations and practices.

Clearly, the core public health action message of this chapter is that there should be earlier, healthier, and more paternal involvement during the perinatal period, in order to improve reproductive and infant health and development and the father's own health and development- "to empower fathers to be active, informed, and emotionally engaged with their children and families" (Levy et al. 2012) from the onset of the pregnancy, if not before. Healthy men and healthy fathers help insure healthy children, healthy families, healthy workforces, and healthy communities.

\section{References}

Alhusen JL, Ray E, Sharps PW, Bullock L (2015) Intimate partner violence during pregnancy: maternal and neonatal outcomes. J Womens Health 24(1):100-106

Alio AP, Mbah AK, Grunsten RA, Salihu HM (2011a) Teenage pregnancy and the influence of paternal involvement on fetal outcomes. J Pediatr Adolesc Gynecol 24(6):404-409

Alio AP, Mbah AK, Kornosky JL, Wathington D, Marty PJ, Salihu HM (2011b) Assessing the impact of paternal involvement on racial/ethnic disparities in infant mortality rates. J Community Health 36(1):63-68

Alio AP, Lewis CA, Scarborough K, Harris K, Fiscella K (2013) A community perspective on the role of fathers during pregnancy: a qualitative study. BMC Pregnancy Childbirth 13(60):13-60 
American Sexual Health Association (2019) Statistics STIs. wwwashasexualhealthorg/stdsstis/ statistics. Accessed 15 Jan 2020

Andersen A-MN, Urhoj SK (2017) Is advanced paternal age a risk factor for the offspring? Fertil Steril 107(2):312-318

Argwal A, Mulgund A, Hamada A, Chyatte MR (2015) A unique view on male infertility around the globe. Reprod Biol Endocrinol 13:37

Bar-Yam NB, Darby L (1997) Fatherhood and breastfeeding: a review of the literature. J Hum Lact 13(1):45-50

Blake-Lamb T, Boudreau AA, Matathia S, Tiburcio E, Perkins ME, Roche B, Kotelchuck M, Shtasel D, Price SN, Taveras EM (2018) Strengthening integration of clinical and public health systems to prevent maternal-child obesity in the first 1,000 days: a collective impact approach. Contemp Clin Trials 65(2):46-52

Bloch JR, Webb DA, Mathews L, Dennis EF, Bennett IM, Culhane JF (2010) Beyond marital status: the quality of the mother-father relationship and its influence on reproductive health behaviors and outcomes among unmarried low income pregnant women. Matern Child Health $\mathbf{J}$ 14:726-734

Bohren MA, Berger BO, Munthe-Kaas H, Tunçalp Ö (2019) Perceptions and experiences of labour companionships: a qualitative evidence synthesis. Cochrane Database Syst Rev 3(3): CD012449. https://doi.org/10.1002/14651858.CD012449.pub2

Boll C, Leppin J, Reich N (2014) Paternal childcare and paternal leave policies: evidence from industrialized countries. Rev Econ Househ 12:129-158

Braveman P, Gottlieb L (2014) The social determinants of health: it's time to consider the causes of the causes. Public Health Rep 129(Suppl 2):19-31

Bronte-Tinkew J, Ryan S, Carrano J, Moore KA (2007) Resident fathers' pregnancy intentions, prenatal behaviors, and links to involvement with infants. J Marriage Fam 69(4):977-990

Brown SS, Eisenberg L (eds) (1995) The best intentions: unintended pregnancy and the well-being of children and families. National Academy Press, Washington, DC

Brygren LO, Kaati G, Edvinsson S (2001) Longevity determined by paternal ancestors' nutrition during the slow growth period. Acta Biotheor 49:53-59

Carlsen E, Giwercman A, Keiding N, Shakkebaek NE (1992) Evidence for the decreasing quality of semen during the past 50 years. Br Med J 305:609. https://doi.org/10.1136/bmj.306.6854.609

Centers for Disease Control and Prevention (CDC) (2011) Updated recommendations for use of tetanus toxoid, reduced diphtheria toxoid and acellular pertussis vaccine (Tdap) in pregnant women and persons who have or anticipate having close contact with an infant aged $<$ 12 months-Advisory Committee on Immunization Practices (ACIP). Morb Mortal Wkly Rep 60(41):1424-1426

Centers for Disease Control and Prevention (CDC) (2019a) Preconception health and health care. https://www.cdc.gov/preconception/index. Accessed 15 Jan 2020

Centers for Disease Control and Prevention (CDC) (2019b) Infertility. https://www.cdc.gov/nchs/ fastats/infertility.htm. Accessed 15 Jan 2020

Centers for Disease Control and Prevention (CDC) (2019c) Sexually transmitted diseases (STDs). https://www.cdc.gov/std/healthcomm/fact_sheets. Accessed 15 Jan 2020

Chabot MJ, Lewis C, de Bocanegra HT, Darney P (2011) Correlates of receiving reproductive health care services among U.S. men aged 15-44. Am J Mens Health 5(4):358-366

Chen P-H, Rovi S, Vega ML, Barrett T, Pan K-Y, Johnson MS (2017) Birth outcomes in relation to intimate partner violence. J Natl Med Assoc 109(4):238-245

Cheng D, Schwarz EB, Douglas E, Horon I (2009) Unintended pregnancy and associated maternal preconception, prenatal and postpartum behaviors. Contraception 79(3):194-198

Cheng E, Rifas-Shiman S, Perkins M, Rich-Edwards J, Gillman M, Wright R, Taveras E (2016) The influence of antenatal partner support on pregnancy outcomes. J Womens Health 25 (7):672-679. https://doi.org/10.1089/jwh.2015.5462

Choiriyyah I, Sonenstein FL, Astone NM, Pleck JH, Dariotis JK, Marcell AV (2015) Men aged 15-44 in need of preconception care. Matern Child Health J 19(11):2358-2365 
Chu SY, Goodwin MM, D'Angelo DV (2010) Physical violence against U.S. women around the time of pregnancy, 2004-2007. Am J Prev Med 38(3):317-322

Collins JW, Rankin KM, Desisto C, David RJ (2019) Early and late preterm birth rates among US-born urban women: the effects of men's lifelong class status. Matern Child Health J 23 (10):1619-1626

Cormon H, Noonan K, Carrol A, Reichman NE (2009) Low-income father's access to health insurance. J Health Care Poor Underserved 20(1):152-164

Cuffe KM, Newton-Levinson A, Gift TL, McFarlane M, Leichliter JS (2016) Sexually transmitted infections testing among adolescents and young adults in the U.S. J Adolesc Health 58 (5):512-519

Curley JP, Mashoodh R, Champagne FA (2011) Epigenetics and the origins of paternal effects. Horm Behav 59(3):306-314

Davison KK, Charles JN, Khandpur N, Nelson TJ (2017) Fathers' perceived reasons for their underrepresentation in child health research and strategies to increase their involvement. Matern Child Health J 21(2):267-274

Davison KK, Gavarkovs A, McBride B, Kotelchuck M, Levy R, Taveras EM (2019) Engaging fathers in early obesity prevention during the first thousand days: policy, systems and environmental change strategies. Obesity 27(4):523-533

Day J, Savani S, Krempley BD, Nguyen M, Kitlinska JB (2016) Influence of paternal preconception exposures on their offspring: through epigenetics to phenotype. Am J Stem Cells 5(1):11-18

de Jonge CJ, Barratt CLR (eds) (2006) The sperm cell: production, maturation, fertilization, regeneration. Cambridge University Press, Cambridge

de Kretser DM (1997) Male infertility. Lancet 349(9054):787-790

Devries KM, Kishor S, Johnson H, Stöckl H, Bacchus LJ, Garcia-Moreno C, Watts C (2010) Intimate partner violence during pregnancy: analysis of prevalence from 19 countries. Reprod Health Matters 18(36):158-171

Dietz DM, LaPlanta Q, Watts EL, Hodes GE, Russo SJ, Feng J, Oosting RS, Vialoua V, Nestler EJ (2011) Paternal transmission of stress-induced pathologies. Biol Psychiatry 70(5):408-411

DiPietro JA (2012) Maternal stress in pregnancy: considerations for fetal development. J Adolesc Health 51(2 Suppl):S3-S8

Dodd JM, Du Plessis LE, Deussen AR, Grivell RM, Yelland LN, Louise J, Mcphee AJ, Robinson JS, Owens JA (2017) Paternal obesity modifies the effect of an antenatal lifestyle intervention in women who are overweight or obese on newborn anthropometry. Sci Rep 7(1):1557. https://doi. org/10.1038/s41598-017-01672-w

Edvardsson K, Lindkvist M, Eurenius E, Mogren I, Small R, Ivarsson A (2013) A population-based study of overweight and obesity in expectant parents: socio-demographic patterns and withincouple associations. BMC Public Health 13(1):923. https://doi.org/10.1186/1471-2458-13-923

Elsenbruch S, Benson S, Rücke M, Rose M, Dudenhausen J, Pincus-Knackstedt MK, Klapp BF, Arck PC (2007) Social support during pregnancy: effects on maternal depressive symptoms, smoking and pregnancy outcome. Hum Reprod 22(3):869-877

Erlandson K, Lindgren H (2011) Being a resource for both mother and child: fathers' experiences following a complicated birth. J Perinat Educ 20(2):91-99

Esquinas G, García-Esquinas E, Aragonés N, Fernández MA, García-Sagredo JM, de León A, de Paz C, Pérez-Meixeira AM, Gil E, Iriso A, Cisneros M, de Santos A, Sanz JC, García JF, Asensio Á, Vioque J, López-Abente G, Astray J, Pollán M, Martínez M, González MJ, PérezGómez B (2014) Newborns and low to moderate prenatal environmental lead exposure: might fathers be the key? Environ Sci Pollut Res 21(13):7886-7898

Finegersh A, Rompal GR, Martin DIK, Homanics GE (2015) Drinking beyond a lifetime: new and emerging insights into paternal alcohol exposure on subsequent generations. Alcohol 49 (5):461-470

Freeman E, Fletcher R, Collins CE, Morgan PJ, Burrows T, Callister R (2012) Preventing and treating childhood obesity: time to include the father. Int J Obes 36(1):12-15 
Frey KA, Navarro SM, Kotelchuck M, Michael CL (2008) The clinical content of preconception care: preconception care for men. Am J Obstet Gynecol 199(6 Suppl B):S389-S395

Frey KA, Engle R, Noble B (2012) Preconception healthcare: what do men know and believe? J Men's Health 9(1):25-35

Gage JD, Everett KD, Bullock L (2007) A review of research literature addressing male partners and smoking during pregnancy. J Obstet Gynecol Neonatal Nurs 36(6):574-580

Garfield CF (2018) Toward better understanding of how fathers contribute to their offspring's health. Pediatrics 141(1):e20173461

Garfield CF, Isacco A (2009) Urban fathers' role in maternal postpartum mental health maternal postpartum mental health. Fathering 7(3):286-302

Gaudino JA, Jenkins B, Rochat RW (1999) No father's names: a risk factor for infant mortality in the state of Georgia, USA. Soc Sci Med 48(2):253-265

Gault B, Hartmann H, Hegerwisch A, Milli J, Cruse LR (2014) Paid parental leave in the United States: what data tells us about access, usage, and economic and health benefits. Institute for Women's Policy Research, Washington, DC

Gavin L, Moskosky S, Carter M, Curtis K, Glass E, Godfrey E, Marcell A, Mautone-Smith N, Pazol K, Tepper N, Zapata L (2014) Providing quality family planning services: recommendations of CDC and the U.S. Office of Population Affairs. Morb Mortal Wkly Rep 63 (RR-04):1-54

Gemayel DJ, Wiener KKK, Saliba AJ (2018) Development of a conception framework that identifies factors and challenges impacting perinatal fathers. Heliyon 4(7):e00694

Geronimus AT (1992) The weathering hypothesis and the health of African-American women and infants: evidence and speculation. Ethn Dis 2(3):207-221

Geronimus AT (1996) Black/white differences in the relationship of maternal age to birthweight: a population-based test of the weathering hypothesis. Soc Sci Med 42(4):589-597

Gerstel N, Clawson D (2018) Control over time: employers, workers, families shaping work schedules. Annu Rev Sociol 44:77-97

Ghosh JKC, Wilhelm MH, Dunkel-Schetter C, Lombardi CA, Ritz BR (2010) Paternal support and preterm birth, and the moderation of effects of chronic stress: a study of Los Angeles County mothers. Arch Womens Ment Health 13(4):327-338

Grady WR, Tanfer K, Billy JOG, Lincoln-Hanson J (1996) Men's perceptions of their roles and responsibilities regarding sex, contraception, and childrearing. Fam Plan Perspect 28 (5):221-226

Halfon N, Larson K, Lu M, Tullis E, Russ S (2014) Lifecourse health development: past, present, future. Matern Child Health J 18(2):344-365

Hardie K, Croce-Galis M, Gay J (2017) Are men well served by family planning programs. Reprod Health 14:14. https://doi.org/10.1186/s12978-017-0278-5

Hehar H, Mychasiuk R (2015) Do fathers matter: influencing neural phenotypes through non-genetic transmission of paternal experiences? Non Genet Inherit 2(1):23-31. https://doi. org/10.1515/ngi-2015-004

Hibbs SD, Rankin KM, DeSisto C, Collins JW Jr (2018) The age-related patterns of pre-term birth among urban African-American and non-Latina white mothers: effects of father-involvement. Soc Sci Med 211:16-20

Hobel CJ, Goldstein A, Barrett ES (2008) Psychosocial stress and pregnancy outcomes. Clin Obstset Gynecol 51(2):333-348

Hohmann-Marriott B (2009) The couple context of pregnancy and its effects on prenatal care and birth outcomes. Matern Child Health J 13:745-754

Hossain Z, Field T, Gonzalez J, Malphurs J, Del Valle C, Pickens J (1994) Infants of depressed mothers interact better with non-depressed fathers. Infant Ment Health J 15(4):348-357

Huerta MdC, Adema W, Baxter J, Han W-J, Lausten M, Lee RH, Waldfogel J (2013) Fathers' leave, fathers' involvement and child development: are they related? Evidence from four OECD countries. OECD social, employment and migration working papers, no. 140 
Jewkes R, Flood M, Lang J (2015) From work with men and boys to changes in social norms and reduction of inequalities in gender relations: a conceptual shift in prevention of violence against women and girls. Lancet 385:1580-1589

Johansson M, Fenwick J, Premberg A (2015) A meta-synthesis of the father's experiences of their partner's labour and birth. Midwifery 31(1):9-18

Johnson K, Posner SF, Biermann J, Cordero JF, Atrash HK, Parker CS, Boulet S, Curtis MG (2006) Recommendations to improve preconception health and health care-United States. Morb Mortal Wkly Rep (MMWR) 55(RR-6):1-23

Jomeen J (2017) Fathers in the birth room: choice or coercion? Help or hinderance? J Reprod Infant Psychol 35(4):321-323

Kaati G, Brygren LO, Edvinsson S (2002) Cardiovascular and diabetes mortality determined by nutrition during parents' and grandparents' slow growth period. Eur J Hum Genet 10 (11):682-688

Kainz G, Eliasson M, von Post I (2010) The child's father, an important person for mother's wellbeing during childbirth: a hermeneutic study. Health Care Women Int 31(7):621-635

Knishkowy B, Baker EL (1986) Transmission of occupational disease to family contacts. Am J Ind Med 9(6):543-540

Kong A, Frigge ML, Masson G, Besenbacher S, Sulem P, Magnusson G, Gudjonsson SA, Sigurdsson A, Jonasdottir A, Jonasdottir A, Wong WSW, Sigurdsson G, Walters GB, Steinberg S, Helgason H, Thorleifsson G, Gudbjartsson DF, Helgason A, Magnusson OT, Thorsteinsdottir U, Stefansson K (2012) Rate of de novo mutations and importance of father's age to disease risk. Nature 488(7412):471-475

Kost K, Lindberg LD (2015) Pregnancy intentions, maternal behaviors, and infant health: investigating relationships with new measures and propensity score analysis. Demography 52 (1):83-111

Kotelchuck M (2018) Looking back to move forward: a return to our roots, addressing social determinants across MCH history. In: Verbiest S (ed) Moving life course theory into practice: making change happen. APHA Press, Washington, DC, pp 57-78

Kotelchuck M (2021) The impact of fatherhood on men's health and development. In: GrauGrau M, las Heras, Bowles HR (eds) Engaged fatherhood for men, families and gender equality. Springer, Cham, pp 63-91

Kotelchuck M, Lu MC (2017) Father's role in preconception health. Matern Child Health J 21 (11):2025-2039

Kumar N, Singh AK (2015) Trends of male factor fertility, an important cause of infertility: a review of the literature. J Hum Reprod Sci 8(4):191-196

Lamb ME (1975) Fathers: forgotten contributors to child development. Hum Dev 18(4):245-266

Lamb ME (ed) (2010) The role of the father in child development, 5th edn. Wiley, New York

Leach LS, Poyser C, Cooklin AR, Giallo R (2016) Prevalence and course of anxiety disorders (and symptom levels) in men across the perinatal period: a systematic review. J Affect Disord 190 (15):675-686

Leavitt JW (2010) Make room for daddy: the journey from waiting room to birthing room. University of North Carolina Press, Chapel Hill

Leonard KE, Eiden RD (1999) Husbands and wives drinking: unilateral or bilateral influences among newlyweds in a general population sample. J Stud Alcohol Suppl 13:130-138

Leonardi-Bee J, John Britton J, Venn A (2011) Secondhand smoke and adverse fetal outcomes in nonsmoking pregnant women: a meta-analysis. Pediatrics 127:734-741

Levine H, Jørgensen N, Martino-Andrade A, Mendiola J, Weksler-Derri D, Mindlis I, Pinotti R, Swan SH (2017) Temporal trends in sperm count: a systematic review and meta-regression analysis. Hum Reprod Update 23(6):646-659

Levy RA, Kotelchuck M (2021) Fatherhood and reproductive health in the antenatal period: from men's voices to clinical practice. In: Grau-Grau M, las Heras M, Bowles HR (eds) Engaged fatherhood for men, families and gender equality. Springer, Cham, pp 111-137 
Levy RA, Badalament J, Kotelchuck M (2012) The fatherhood project. Massachusetts General Hospital, Boston. www.thefatherhoodproject.org

Lindberg LD, Kost K (2014) Exploring U.S. men's birth intentions. Matern Child Health J 18 (3):625-633

Lindberg LD, Kost K, Maddow-Zimet I (2016) The role of men's childbearing intentions in father involvement. J Marriage Fam 79(1):44-59

Lobel M, Hamilton JG, Cannella D (2008) Psychosocial perspectives on pregnancy: prenatal maternal stress and coping. Soc Personal Psychol Compass 2(4):1600-1623

Lu MC, Halfon N (2003) Racial and ethnic disparities in birth outcomes: a life-course perspective. Matern Child Health J 7(1):13-30

Ludington-Hoe SM, Hashemi MS, Argote LA, Medellin G, Rey H (1992) Selected physiologic measures and behaviors during paternal skin contact with Columbian pre-term infants. J Dev Physiol 18:223-232

Lui C, Cnattingus S, Bergstrom M, Östberg V, Hjernand A (2016) Prenatal parental depression and preterm birth: a national cohort study. BJOG 132(12):1973-1982

MacDormand MF, Mathews TJ (2010) Behind international rankings of infant mortality: how the United States compares with Europe. Int J Health Serv 40(4):577-588

Madsen SA, Burgess A (2010) Fatherhood and mental health difficulties in the postnatal period. In: Conrad D, White A (eds) Promoting men's mental health. Radcliffe Publishing, Oxford, pp $74-82$

Martin LT, McNamara MJ, Milot AS, Halle T, Hair EC (2007) The effects of father involvement during pregnancy on receipt of prenatal care and maternal smoking. Matern Child Health $\mathrm{J} 11$ (6):595-602

May C, Fletcher R (2013) Preparing fathers for the transition to parenthood: recommendations for the content of antenatal education. Midwifery 29(5):474-478

Meeker JD, Benedict MD (2013) Infertility, pregnancy loss and adverse birth outcomes in relation to maternal secondhand tobacco smoke exposure. Curr Womens Health Rev 9(1):41-49

Mezilius AH, Hyde JS, Clark R (2004) Father involvement moderates the effect of maternal depression during a child's infancy on behavior problems in kindergarten. J Fam Psychiatry 18(4):575-588

Misra DP, Caldwell C, Young AA, Abelson S (2010) Do fathers matter? Paternal contributions to birth outcomes and racial disparities. Am J Obstet Gynecol 202(2):99-100

Moos M-K (2003) Preconceptional wellness as a routine objective for women's health care: an integrative strategy. J Obstet Gynecol Neonatal Nurs 32(4):550-556

Morgan PJ, Young MD, Lloyd AB, Wang ML, Eather N, Miller A, Murtagh EM, Barnes AT, Pagoto SL (2017) Involvement of fathers in pediatrics obesity prevention and treatment trials: a systematic review. Pediatrics 139(2):e20162635

Mosher WD, Jones J, Abma JC (2012) Intended and unintended births in the United States: 1982-2010. Natl Health Stat Rep 55(55):1-28

Moss JL, Harris KM (2015) Impact of maternal and paternal preconception health on birth outcomes using prospective couples' data in add health. Arch Gynecol Obstet 291(2):287-298

Mychasiuk R, Harker A, Ilnytskyy S, Gibb R (2013) Paternal stress prior to conception alters DNA methylation and behaviour of developing rat offspring. Neuroscience 241:100-105

National Academies of Sciences, Engineering, and Medicine (NASEM) (2016) Parenting matters: supporting parents of children ages 0-8. The National Academies Press, Washington, DC

National Academies of Sciences, Engineering, and Medicine (NASEM) (2019a) Vibrant and healthy kids: aligning science, practice, and policy to advance health equity. The National Academies Press, Washington, DC

National Academies of Sciences, Engineering, and Medicine (NASEM) (2019b) A roadmap to reducing child poverty. National Academies Press, Washington DC

Nepomnyaschy L, Waldfogel J (2007) Paternity leave and fathers' involvement with their young children: evidence from the American ECLS-B. Community Work Fam 10(4):427-453 
Ngo AD, Taylor R, Roberts CL, Nguyen TV (2006) Association between agent orange and birth defects: systematic review and meta-analysis. Int J Epidemiol 35(5):1220-1230

Noncent E, Lawson AK, Mendoza G, Brannigan RE, Marsh EE (2017) Will I ever be a dad? Distress, appraisal and coping in male infertility patients. Fertil Steril 108(3 Suppl):e301-e302

Northstone K, Golding J, Smith GD, Miller LL, Pembrey M (2014) Prepubertal start of father's smoking and increased body fat in his sons: further characterisation of paternal transgenerational responses. Eur J Hum Genet 22(12):1382-1386

O’Brien AP, Hurley J, Linsley P, McNeil KA, Fletcher R, Aitken JR (2018) Men's preconception health: a primary health care viewpoint. Am J Mens Health 12(5):1575-1581

O'Campo P, Urquia M (2011) Aligning method with theory: a comparison of two approaches to modeling the social determinants of health. Matern Child Health J 16(9):1870-1878

O'Campo P, Burke JG, Culhane J, Elo IT, Eyster J, Holzman C, Messer LC, Kaufman JS, Laraia BA (2008) Neighborhood deprivation and pre-term birth among non-Hispanic black and white women in eight geographic areas in the United States. Am J Epidemiol 67(2):155-163

Palladino C, Singh V, Campbell J, Flynn H, Gold K (2011) Homicide and suicide during the perinatal period: findings from the National Violent Death Reporting System. Obstet Gynecol 118(5):1056-1063

Pang TYC, Short AK, Bredy TW, Hannan AJ (2017) Transgenerational paternal transmission of acquired traits: stress-induced modification of the gene regulatory transcriptome and offspring phenotypes. Curr Opin Behav Sci 14(1):140-147

Paulson JF, Bazemore SD (2010) Prenatal and postpartum depression in fathers and its association with maternal depression: a meta-analysis. JAMA 303(19):1961-1969

Persson P, Rossin-Slater M (2019) When dad can stay home: fathers' workplace flexibility and maternal health. IZA Institute of Labor Economics discussion paper no. 12386

Philpott LF, Leahy-Warren P, FitzGerald S, Savage E (2017) Stress in fathers in the perinatal period: a systematic review. Midwifery 55:113-127

Philpott LF, Savage E, FitzGerald S, Leahy-Warren P (2019) Anxiety in fathers in the perinatal period: a systemic review. Midwifery 76:54-101

Pies C, Kotelchuck M (2014) Bringing the MCH life course perspective to life. Matern Child Health J 18(2):335-338

Redshaw M, Heikkilä K (2010.0 Delivered with care. A national survey of women's experience of maternity care 2010. Technical report. National Perinatal Epidemiology Unit, University of Oxford, United Kingdom. https://researchonline.lshtm.ac.uk/id/eprint/2548656

Redshaw M, Henderson J (2013) Father engagement in pregnancy and child health: evidence from a national survey. BMC Pregnancy Childbirth 13:70

Rempel LA, Rempel JK (2011) The breastfeeding team: the role of involved fathers in the breastfeeding family. J Hum Lact 27(2):115-121

Rodgers AB, Morgan CP, Bronson SL, Revello S, Bale TL (2013) Paternal stress exposure alters sperm microRNA content and reprograms offspring HPA stress Axis regulation. J Neurosci 33 (21):9003-9012

Romanov H, Pilkington PD, Giallo R, Whelan TA (2016) A systematic review of interventions targeting paternal mental health in the perinatal period. Infant Ment Health J 37(3):289-301

Salmasi G, Grady R, Jones J, McDonald SD (2010) Environmental tobacco smoke exposure and perinatal outcomes: a systematic review and meta-analyses. Acta Obstet Gynecol Scand 89 (4):423-441

Sangi-Haghpeykar H, Mehta M, Posner S, Poindexter AN, III (2005) Paternal influences on the timing of prenatal care among Hispanics. Matern Child Health J 9(2):159-163

Saxbe D, Corner G, Khaled M, Horton K, Wu B, Khoddam H (2018) The weight of fatherhood: identifying mechanisms to explain paternal perinatal weight gain. Health Psychol Rev 12 (3): $1-38$

Sedgh G, Singh S, Hussain R (2014) Intended and unintended pregnancies worldwide 2012 and recent trends. Stud Fam Plan 45(3):301-314 
Shah PS, the Knowledge Synthesis Group on Determinants of Preterm/Low Birthweight Births (2010) Paternal factors and low birth weight preterm, and small for gestational age births: a systematic review. Am J Obstet Gynecol 202(2):103-123

Shah PS, Balkhair T, Ohlsson A, Beyene J, Scott F, Frick C (2011) Intention to become pregnant and low birth weight and preterm birth: systemic review. Matern Child Health J 15(2):205-216

Shapiro GD, Bushnik T, Sheppard AJ, Kramer MS, Kaufman JS, Yang S (2017) Paternal education and adverse birth outcomes in Canada. J Epidemiol Community Health 71(1):67-72

Smith LP, Ng SW, Popkin B (2013) Trends in US home food preparation and consumption: analysis of national nutrition surveys and time use studies from 1965-1966 to 2007-2008. Nutr J 12:45. https://doi.org/10.1186/1475-2891-12-45

Soubry A (2015) Epigenetic inheritance and evolution: a paternal perspective on dietary influences. Prog Biophys Mol Biol 11(1-2):79-85

Soubry A (2018) Epigenetics as a driver of developmental origins of health and disease: did we forget the fathers? BioEssays 40(1). https://doi.org/10.1002/bies.201700113

Soubry A, Guo L, Huang Z, Hoyo C, Romanus S, Price T, Murphy SK (2016) Obesity-related DNA methylation at imprinted genes in human sperm: results from the TIEGER study. Clin Epigenetics 8:51. https://doi.org/10.1186/s13148-016-0217-2

Stanton WR, Lowe JB, Moffatt J, Del CB (2004) Randomised control trial of a smoking cessation intervention directed at men whose partners are pregnant. Prev Med 38(1):6-9

Steen M, Downe S, Bamford N, Edozien L (2012) Not-patient and not-visitor: a metasynthesis father's encounters with pregnancy, birth, and maternity care. Midwifery 28(4):362-371

Sternberg P, Hubley J (2004) Evaluating men's involvement as a strategy in sexual and reproductive health promotion. Health Promot Int 19(3):389-396

Svanes C, Koplin J, Skulstad SM et al (2017) Father's environment before conception and asthma risk in his children: a multi-generational analysis of the respiratory health in northern Europe study. Int J Epidemiol 46(1):235-245

Teitler JO (2001) Father involvement, child, health, and maternal health behavior. Child Youth Serv Rev 23(4-5):403-425

Thaddeus S, Maine D (1994) Too far to walk: maternal mortality in context. Soc Sci Med 38 (8):1091-1110

Treadwell H, Ro M (2008) Poverty, race, and the invisible men. Am J Public Health 98(Suppl 1): S142-S144

Tsui AO, McDonald-Mosley R, Burke AE (2010) Family planning and the burden of unintended pregnancy. Epidemiol Rev 32(1):152-174

Wadhwa PD, Entringer S, Buss C, Michael CL (2011) The contribution of maternal stress to preterm birth: issues and considerations. Clin Perinatol 38(3):351-384

Wadwha PD, Buss C, Entringer S, Swanson JM (2009) Developmental origins of health and disease: brief history of the approach and current focus on epigenetic mechanisms. Semin Reprod Med 27(5):358-368

Whitehead M, Dalgren G (1991) What can be done about inequalities in health? Lancet 338 (8774):1059-1063

Williams DR (2003) The health of men: structured inequalities and opportunities. Am J Public Health 93(5):724-731

Wise PH (2008) Transforming preconceptional, prenatal, and interconceptional care into a comprehensive commitment to women's health. Womens Health Issues 18(6 Suppl):S13-S18

Wolfberg AJ, Michels KB, Shields W, O’Campo P, Bronner Y, Bienstock J (2004) Dads as breastfeeding advocates: results from a randomized controlled trial of an educational intervention. Am J Obstet Gynecol 191(3):708-712

Woodbury RM (1925) Causal factors in infant mortality: a statistical study based on investigations in eight cities. Children's bureau publication no. 142. Government Printing Office, Washington, DC

World Health Organization (WHO) (2007) Fatherhood and heath outcomes in Europe. World Health Organization Regional Office for Europe, Copenhagen 
World Health Organization (WHO) (2017) World health statistics. www.who.int/gho/publications/ world_health_statistics/2017/en/

Wulf D (2002) In their own right: addressing the sexual and reproductive health needs of American men. Alan Guttmacher Institute, New York

Yogman MW, Eppel AM (2021) The role fathers in child and family health. In: Grau-Grau M, las Heras M, Bowles HR (eds) Engaged fatherhood for men, families and gender equality. Springer, Cham, pp 15-30

Yogman MW, Garfield CF, the Committee on Psychosocial Aspects of Child and Family Health (2016) Fathers' roles in the care and development of their children: the role of pediatricians. Pediatrics 138(1):e20161128

Open Access This chapter is licensed under the terms of the Creative Commons Attribution 4.0 International License (http://creativecommons.org/licenses/by/4.0/), which permits use, sharing, adaptation, distribution and reproduction in any medium or format, as long as you give appropriate credit to the original author(s) and the source, provide a link to the Creative Commons license and indicate if changes were made.

The images or other third party material in this chapter are included in the chapter's Creative Commons license, unless indicated otherwise in a credit line to the material. If material is not included in the chapter's Creative Commons license and your intended use is not permitted by statutory regulation or exceeds the permitted use, you will need to obtain permission directly from the copyright holder. 